\title{
Going Green in Marin County
}

\author{
Alex HINDS
}

Green design, sustainable development and sustainable cities were the themes of Alex Hinds' talk at Cal Poly's College of Architecture and Environmental Design Hearst Lecture Series in the fall of 2008. Alex was Marin County's community development director and coordinated the 2007 general plan update, a pioneer effort in planning for sustainability.

Fossil fuel and resource consumption-related issues such as climate change, water quality and quantity, and a host of socioeconomic concerns have prompted California state and municipal governments to pursue sustainable development strategies. Towards that end, nine cities and Marin County representing more than 8 million California residents banded together in 2006 to form Green Cities California.

While many communities have undertaken a variety of initiatives, this paper will focus on the 2007 update of the Marin Countywide Plan and its theme of "planning sustainable communities". This paper will also discuss how implementation of the Plan is being monitored through a system of benchmarks, indicators, and targets.

Historically, the Marin Countywide Plan has employed a series of environmental corridors as the basic framework for regulating land use, consisting of: the Coastal Recreation Corridor, Inland Rural Corridor, and City-Centered Corridor. In the latest update of the Countywide Plan, a Baylands Corridor was added to further recognize the importance of historic baylands along the shoreline of San Francisco and San Pablo Bays- especially in light of climate change and potential sea level rise.
Alex Hinds was a visiting instructor at Cal Poly's CRP program in fall 2008. He previously served as the community development director for Marin County and the planning and building director of San Luis Obispo County. He is currently the interim director of Sonoma State University's Center for Sustainable Communities.

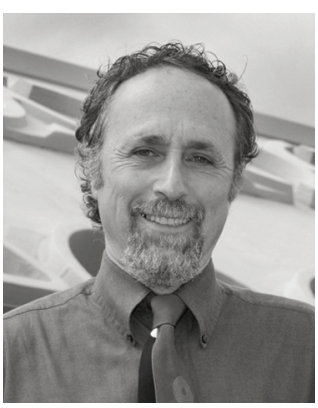

\section{What is Sustainability?}

According to the Plan (Marin County Community Development Agency, 2007), "Sustainability is defined as aligning our built environment and socioeconomic activities with the natural systems that support life. In the long run, sustainability means adapting human activities to the constraints and opportunities of nature. Central to this definition is meeting the needs of both the present and the future."

An important measure of sustainability is the calculation of an area or population's ecological footprint. Today, over 24 global acres are needed to support the consumption of the average United State's resident - if everyone on the globe consumed at this level, five planets would be required (Global Footprint Network, 2006). In 2001 Marin County became the first United States municipality to calculate its ecological footprint, at 27.5 global acres per person, more than double that of many European countries; slightly higher than that of the average American - and other San Francisco Bay area counties (Fig. 2).

The economist Herman Daly (1989) designed a conceptual framework that integrates natural systems, social systems and human aspirations.

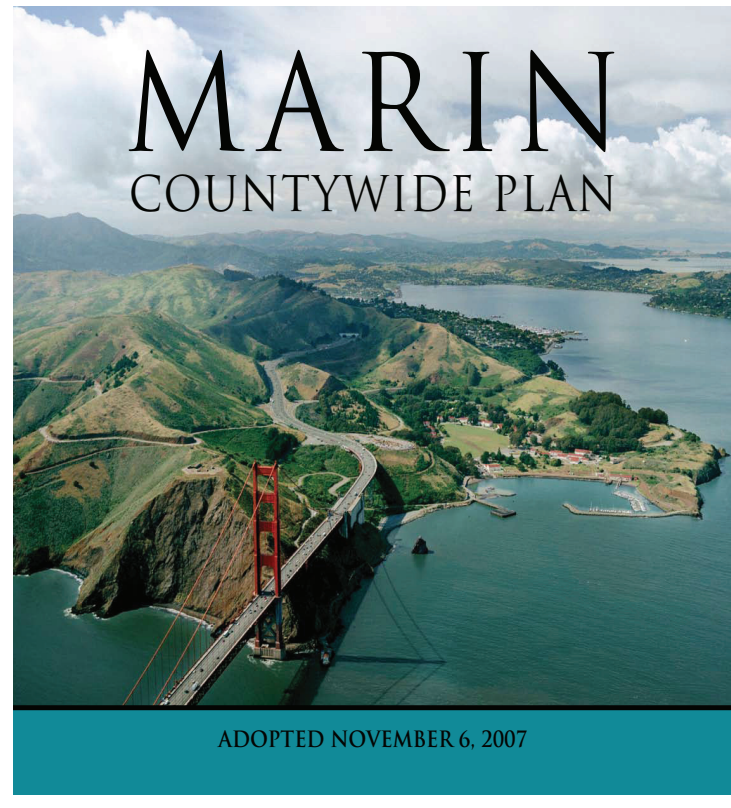


Figure 2

Comparative ecological footprints.

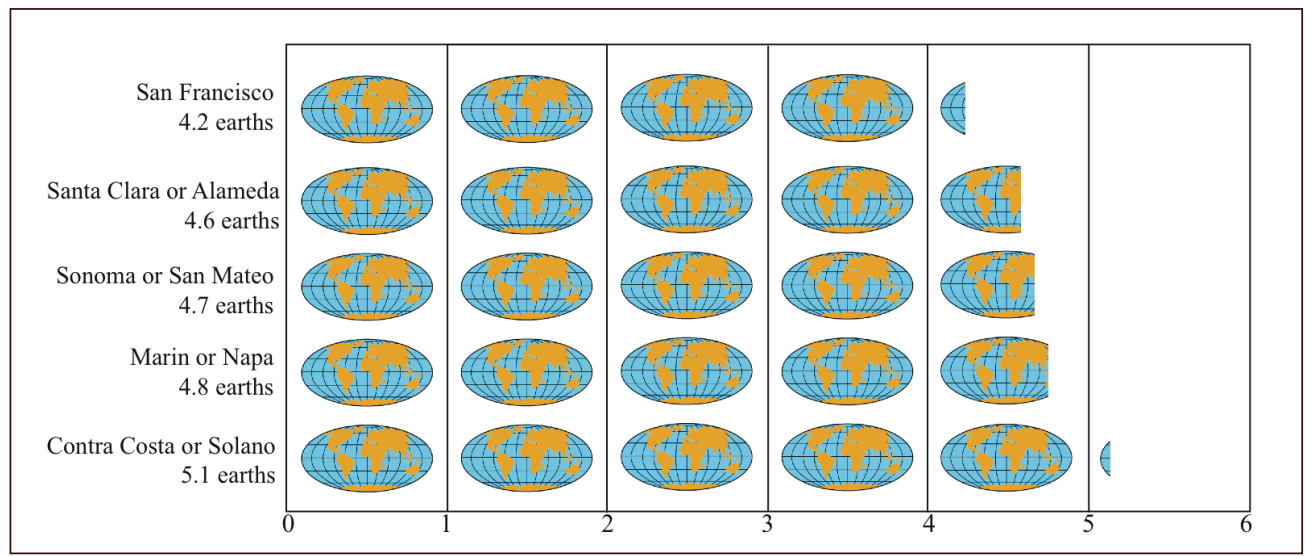

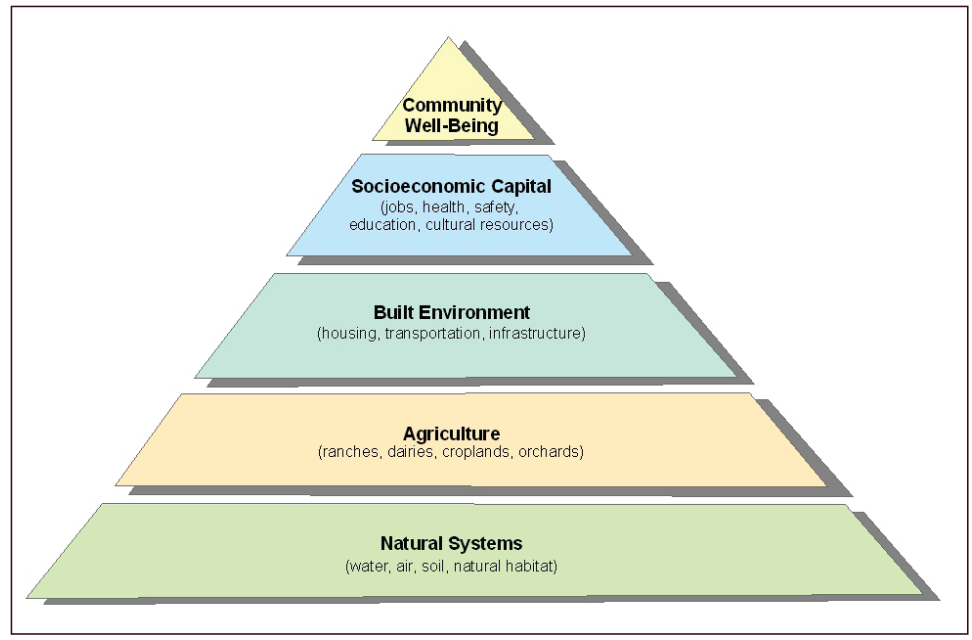

Figure 3

Modified version of Daly's conceptual model of sustainability.
Figure 3 represents a modified version of Daly's conceptual scheme, to more closely correlate to the organization of the Marin Countywide Plan, the base of this triangle consists of natural systems, such as water, air, soil, and natural habitats that support life. The illustration depicts the mutually supportive relationship of natural and built environments as the foundation of economic and social wellbeing.

\section{How is the Countywide Plan Organized?}

The updated Countywide Plan is reorganized into three sections as follows:

The Natural Systems Element focuses on "Nature, agriculture, and life support systems including:

- biological resources

- water resources

- environmental hazards

- atmosphere and climate

- open space

- trails

- agriculture and food

The Built Environment Element addresses villages, towns and construction-related activities including:

- community development

- community design

- energy and green building

- mineral resources

- housing

- transportation

- community facilities 
The Socioeconomic Element focuses on people and what they do for each other including:

- the economy

- childcare

- public safety

- community participation

- diversity

- education

- environmental justice

- public health

- arts and culture

- historical and archaeological resources

- parks and recreation

Most legally mandated general plan topics are included in the first two elements. Each element of the Plan is also organized to answer the following questions:

-What are the desired outcomes?

- Why is it important?

- How will results be achieved?

- How will success be measured?

Furthermore, each goal in the Plan is evaluated in terms of its potential environmental, economic, and (social) equity benefits.

\section{How is Implementation Monitored?}

Implementation of the Countywide Plan is being monitored through a system of approximately 70 benchmarks, indicators, and targets. Toward this end, the Plan set a nonbinding target of 250 certified green businesses by 2010, and 15 MW of installed solar photovoltaic electricity by 2015 . By visiting the Marin Countywide Plan website at www.future-marin.org and clicking on the NewSee -it viewer, interested parties can review the status of individual targets contained in the Plan. For example, according to the website, as of December 2008, there were already slightly more than 250 certified green businesses and around 7.5 MW of installed solar photovoltaic electricity countywide. Nevertheless, progress towards achieving many of the targets listed in the Plan will inevitably vary and this monitoring system is intended to provide a forum for reviewing and adjusting targets and implementation strategies as appropriate.

\section{References}

Daly, Herman and Cobb, John. 1989. For the Common Good. Redirecting the Economy toward Community, the Environment, and a Sustainable Future. Boston, MA; Beacon Press.

Global Footprint Network. 2006. Ecological Footprint Overview. Oakland, CA.

Marin County Community Development Agency. 2006. Measuring the Effect of the Countywide Plan on Marin's Ecological Footprint. San Rafael, CA.

Marin Community Development Agency. 2007. Marin Countywide Plan. San Rafael, CA.

Redefining Progress. 2004. Bay Area Indicators: Measuring Progress Toward Sustainability. Oakland, CA. 